\title{
La evolución de los Derechos Humanos: una mirada desde las Relaciones Internacionales*
}

\author{
Pedro Piedrahita Bustamante \\ Universidad de Medellín, Medellín, Colombia \\ ppiedrahita@udem.edu.co \\ https://orcid.org/0000-0001-6408-0431
}

\section{RESUMEN}

El objetivo del artículo es evidenciar la evolución política de los Derechos Humanos y así entender su relevancia en las relaciones internacionales contemporáneas, debido a que los Derechos Humanos se han convertido en el principal instrumento de legitimación política en Occidente. Esto se realiza a partir de los tres niveles de análisis que fueron formulados por Kenneth Waltz (1959): individual, estatal e interna- cional. De esta forma, se sostiene que la manifestación de los Derechos Humanos a nivel internacional ha sido un producto de procesos de guerra y posguerra que terminaron configurando la humanización de la guerra y el marco normativo internacional de protección de derechos.

Palabras clave: Derechos Humanos; Occidente; modernidad; Relaciones Internacionales.

Cómo citar: Piedrahíta Bustamante, P. (2018). La evolución de los Derechos Humanos: una mirada desde las relaciones internacionales. Ciencias Sociales y Educación, 7(14). 149-164. DOI: https://doi.org/10.22395/csye. v7n14a8

Recibido: 30 de mayo de 2018.

Aprobado: 2 de agosto de 2018. 


\section{The Evolution of Human Rights from the International Relations Point of View}

\section{ABSTRACT}

The purpose of this article is putting into evidence the political evolution of Human Rights and thus understanding its importance in the contemporary international relations, given that the Human Rights has become the main instrument for political legitimacy in the West. This is made from three levels of analysis that were stated by Kenneth Waltz (1959): the individual, the state and the international levels. In this manner, it is held that the display of Human Rights in an international level has been a product of war and post-war processes that ended up setting the humanization of war and the normative framework for the protection of rights.

Keywords: Human Rights; West, modernity; International Relations.

\section{A evolução dos Direitos Humanos: uma mirada desde as relações internacionais}

\section{RESUMO}

O objetivo deste artigo é tornar evidente a evolução política dos Direitos Humanos e, assim, entender sua relevância nas relações internacionais contemporâneas, devido a que os Direitos Humanos se converteram no principal instrumento de legitimação política no Ocidente. Isso é realizado a partir dos três níveis de análise que foram formulados por Kenneth Waltz (1959): individual, estatal e internacional. Dessa forma, argumenta-se que a manifestação dos Direitos Humanos no âmbito internacional tem sido um produto de processos de guerra e pós-guerra que acabaram configurando a humanização da guerra e o referencial normativo internacional de proteção de direitos.

Palavras-chave: Direitos Humanos; Ocidente; modernidade; Relações Internacionais. 


\section{Introducción}

Los Derechos Humanos —en adelante DDHH— se han convertido en el principal instrumento de legitimación política en Occidente. Esta premisa es necesario explicarla desde la historia, la cual es fundamental en la ciencia política para entender los hechos particulares que configuran las dinámicas del poder político. En este orden de ideas, este artículo tiene como objetivo evidenciar la evolución política de los DDHH para entender su relevancia en las relaciones internacionales. Esto se realiza siguiendo los tres niveles de análisis formulados por Kenneth Waltz (1959): individual, estatal e internacional.

Hay que precisar que, si bien en un principio los niveles de Waltz (1959) fueron formulados para entender las dinámicas de la guerra, en la actualidad son utilizados en la ciencia política para elaborar marcos de referencia que permitan entender el sistema y el orden internacional. En pocas palabras, la metodología de los niveles posibilita esbozar la evolución de los DDHH, sus relaciones y su relevancia en la política internacional del mundo contemporáneo.

Como principal referente histórico se abordó el trabajo realizado por la profesora Lynn Hunt (2007) quien sostiene que los DDHH son una invención del siglo XVIII, no fueron un descubrimiento y mucho menos una manifestación divina. En su planteamiento la autora desarrolla un enfoque en el que aclara las condiciones sociales y el conocimiento necesario para el surgimiento del concepto. También son fuentes importantes de este artículo los trabajos de Donald Kagan (2003) y Henry Kissinger (2001).

Se advierte que este artículo está dentro de los marcos de lo que se podría denominar perspectiva occidental, debido a que se aborda la evolución de los DDHH desde la óptica de la cultura occidental. De acuerdo con Peter Frankopan (2016), entender el mundo desde la historia tradicional eurocéntrica occidental basada en la idea de que:

la Grecia antigua engendró a Roma, Roma engendró la Europa cristiana, la Europa cristiana engendró el Renacimiento, el Renacimiento engendró la Ilustración, la Ilustración engendró la democracia política y la revolución industrial. La industria se mezcló con la democracia para engendrar a su vez a los Estados Unidos, la encarnación de los derechos a la vida, la libertad y la búsqueda de la felicidad (pp. 13-14).

Lo anterior implica tres cosas: primero, que existe un reconocimiento implícito que el mundo no se limita exclusivamente a Occidente y que la evolución de los DDHH en otras culturas puede ser diferente. Segundo, como consecuencia de lo anterior, que en este texto no se aborda la evolución de los DDHH en otras culturas y, tercero, que se parte de la idea de que el relato occidental ha sido dominante en el mundo desde el siglo XX. 
En este orden de ideas, dicho relato ${ }^{1}$ se ha impuesto a través de la expansión del Estado moderno, la economía que parte de la industrialización y el establecimiento de un orden internacional que se basa en el Estado nación, el cual, durante los siglos XIX y XX, se cimentó bajo el principio de crear un vínculo social desde la identidad política, los procesos de integración social, política y económica (Patiño, 2005, p. 205).

El texto se desarrolla en tres partes: primero, el nivel individual, donde se describen los orígenes de la evolución de los DDHH a partir de elementos como la sociabilidad, la empatía y la ampliación del umbral de la vergüenza. Asimismo, de la relación de la modernidad y de la modificación de las mentes individuales en la transición de una vida marcada por el Él a una por el Yo. Segundo, el nivel estatal en el que se establece la relación de los Estados con los DDHH a través de la democracia liberal, la libertad individual y el reconocimiento de la dignidad. Tercero, el nivel internacional en el que se evidencia los DDHH en las relaciones internacionales a partir de la descripción de algunos hechos históricos asociados a la guerra, pero que al final terminan configurando la humanización de la guerra y el marco normativo internacional de protección de DDHH.

\section{El nivel individual}

La profesora Lynn Hunt (2007) propone entender los DDHH desde una perspectiva histórica que permita dimensionar un significado más allá de las diferentes declaraciones $^{2}$. Para esto, lo primero que afirma es que los derechos surgen en una época específica de la historia, en el siglo XVIII. Además, establece que no es preciso hablar de descubrimiento, sino de invención, lo que da lugar a que se hablara de los derechos como pertenecientes al género humano, los cuales tuvieron fuentes sociales, artísticas, políticas, económicas e ideológicas.

Por otro lado, la autora cuestiona la "evidencia"3 de los derechos al preguntar: "¿Pueden ser «evidentes», cuando los estudiosos llevan más de doscientos años discutiendo lo que quiso decir Jefferson con esta palabra?" (Hunt, 2007, p. 18). En esta línea, señala que los DDHH, además de ser incorporados como universales e iguales para todos, deben tener contenido político, característica que los exalta

\footnotetext{
1 "Las sociedades occidentales se rigen por la creencia que la modernidad es una condición única, algo que es en todas partes igual y siempre benigno. A medida que las sociedades se hacen más modernas, también se vuelven más semejantes. Y al mismo tiempo se hacen mejores. Ser moderno significa realizar nuestros valores: los valores de la ilustración tal como nos gusta concebirlos" (Gray, 2004, p. 13).

2 Algunas declaraciones de derechos son: 1) Declaración de Independencia de los Estados Unidos de junio de 1976; 2) Declaración de los Derechos del Hombre y del Ciudadano de agosto de 1789 y 3) Declaración Universal de Derechos Humanos de diciembre de 1948.

3 En las tres declaraciones de Derechos Humanos es común encontrar: "sostenemos como evidentes estas verdades". Al respecto ver: Hunt (2007): capítulo introductorio.
} 
como una pieza fundamental y les otorga a su carácter una dimensión social, la cual se explica cuando afirma que:

No son los derechos de los seres humanos en la naturaleza; son los derechos de los seres humanos en sociedad. No son tan solo derechos humanos en contraposición a derechos divinos, o derechos humanos en contraposición a los derechos de los animales; son los derechos de los seres humanos en relación con sus semejantes (Hunt, 2007, p. 19).

Dice Hunt que, en general, los DDHH se han abordado desde una dimensión jurídica y filosófica; así los concebía el mismo Thomas Jefferson (2007, p. 21). Sin embargo, considera que los DDHH se hacen evidentes cuando la propia concepción de los individuos se transforma y se convierte en una forma diferente de relación con los demás, la cual se hace explícita a lo largo del siglo XVIII con el cambio en la mentalidad y en las relaciones de los individuos en sociedad. Este cambio de mentalidad estuvo marcado por la transición de un relato de la vida de las personas marcadas por el Él a uno marcado por el Yo. Es decir, lo que en palabras del filósofo francés Alain Renaut (1993) es la creación del sujeto individual. De acuerdo con Patiño (2005) el individuo es el que "da sentido a la mayoría de las reivindicaciones políticas de nuestras sociedades occidentales y a las nociones de libertad, justicia, ordenamiento, cohesión social que conocemos y que se debaten políticamente (p.170)".

En esta misma línea, Taylor (1996) establece, en su estudio sobre las prácticas sociales de la identidad moderna en la historia, que hubo cambios en la religión, la política, la economía, la intelectualidad y el arte que permitieron una transformación en los seres humanos. Dentro de esta perspectiva, Hunt (2007) encuentra en las novelas epistolares del siglo XVIII un fundamento claro para afirmar que la mentalidad acerca de lo que eran tanto los hombres como las mujeres, y la forma como cambiaban los sentimientos, las expresiones del amor, del afecto y su concepción del cuerpo, fueron fundamentales, en tanto, dan cuenta de que la humanidad estaba alcanzando altos niveles de autonomía y empatía (Hunt, 2007, p. 28). El efecto de esto fue la separación de los individuos de las concepciones jerárquicas y divinas de relacionamiento (la de los padres, la de la iglesia, la del señor) hasta llegar a concebirse a sí mismos como autónomos y capaces de tener sentimientos, sensaciones, ideas y placeres.

Además, para que esto ocurriera fue necesaria la transformación de la idea del cuerpo y la de las mentes individuales. En cuanto al cuerpo, Hunt (2007) señala la ampliación de lo que denomina el "umbral de la vergüenza", pues se van adoptando las normas que conformarán los códigos de higiene y de urbanidad que siguen evolucionando hasta la actualidad. Poco a poco se fue censurando la realización en público de actos fisiológicos como: orinar, defecar o limpiarse el cuerpo con el vestido luego de dichos actos. Se comenzó a asociar el pudor en la 
relación con los demás. Los olores, incluso, empezaron a marcar diferenciaciones con las demás personas. Así se inició un sentido de la intimidad, en tanto defensa de la persona y defensa del ser humano en un ambiente individual.

Concebir que los individuos del siglo XVIII tenían derechos, no como una característica de su ser, sino como la posibilidad de ejercerlos y hacerlos valer frente a los demás, de convertirlos en una actividad, requería que las ideas acerca de los hombres en sociedad se transformaran y que ellos mismos dejaran de verse a sí mismos como quienes debían obediencia, y no razón. Como lo dice Hunt (2007) "para que los derechos humanos se volviesen evidentes, la gente normal y corriente debía disponer de nuevas formas de comprender, que surgieron a partir de nuevos tipos de sentimientos" (p. 33).

Un ejemplo de lo anterior es la influencia que ejerció la novela epistolar en la invención de los derechos humanos (Hunt, 2007, pp. 35-71). Obras como Pamela o Clarissa de Samuel Richardson y Julia de Rousseau, tuvieron éxito en la medida en que existía ya la familiarización con la lectura y fueron anteriores a las declaraciones de derechos, tanto en Norteamérica como en Francia. Afirma la autora que el intercambio de cartas fue un recurso narrativo que facilitó que los individuos pudieran observar la intimidad de los demás, que se despertaran sentimientos hacia esas situaciones y se creara una actitud de unos hacia otros como la empatía, por fuera de las barreras sociales:

Por consiguiente, aprendían a ver a los demás - a los que no conocían personalmente-como seres iguales a ellos, con los mismos tipos de emociones internas. Sin este proceso de aprendizaje, la «igualdad» no podía haber alcanzado ningún sentido profundo ni, en particular, ninguna consecuencia política (Hunt, 2007, pp.39-40).

$\mathrm{Al}$ crearse una actitud diferente frente al otro, se trasladaron los efectos al proceso judicial. Se puso en tela de juicio la tortura y otros castigos degradantes para el ser humano, tal como ocurrió en el gobierno revolucionario francés que en 1789 renunció a la tortura como método judicial y luego para 1792 introdujo la guillotina como un mecanismo que buscaba homogeneizar el cumplimiento de la pena de muerte (Hunt, 2007, p. 77). Entre quienes criticaban esto, estuvo el italiano Cesare Beccaria quien, en su obra De los delitos y las penas, aplicó el nuevo pensamiento de los DDHH y desarrolló principios para un derecho penal entendido de manera diferente a la venganza o a la expiación ${ }^{4}$. Ahora bien ¿Cómo estos hechos que modificaron la esfera más íntima de las personas y la sociabilidad tuvieron un impacto en la concepción política de los Estados? A esta pregunta se responderá en el siguiente acápite.

$4 \quad$ Al respecto ver: Beccaria (2011). 


\section{El nivel estatal}

Según Max Weber (2010) el Estado es "una comunidad humana dentro de los límites de un territorio establecido, ya que este es un elemento que lo distingue, la cual reclama para ella — con el triunfo asegurado— el monopolio de la legítima violencia física" (p. 10). Además, es una forma de organización política moderna que resultó de la conjugación de varios elementos como: la nación, la figura abstracta, la sociedad, el monopolio de la fuerza, la tributación y las burocracias. La figura de la nación está asociada al territorio, que hace del Estado la expresión de una colectividad en un territorio específico (Chevallier, 2014, pp. 35-37).

Dicho lo anterior, la relación que tienen los Estados con los DDHH se entiende desde la democracia liberal. Según Sartori (2014) este tipo de democracia se configuró en los Estados modernos luego de un proceso político que buscó evitar las radicalizaciones y establecer un sistema de control y limitación del poder (p. 173). De tal forma, los Estados democráticos son aquellos que tratan de eliminar la opresión de los hombres sobre los hombres, al llevar a la reivindicación de su libertad individual. Este reconocimiento de la libertad individual en el marco de los DDHH se conoce como dignidad humana.

Por eso, la dignidad humana es la forma para "regular el orden social a fin de superar o evitar, entre otras cosas, la violencia, la guerra o la injusticia" (Suárez, 2004, p. 235). En las constituciones políticas de los Estados democráticos liberales se ha incluido el principio de la dignidad humana, al establecer "el respeto incondicionado del sujeto como capaz de realizar acciones morales, de libertad y de responsabilidad" (Suárez, 2004, p. 234).

La evolución de los DDHH en el nivel estatal tiene una relación directa con la idea de la modernidad, en tanto la razón es el fundamento de la ampliación de las mentes y los cuerpos humanos. De este modo, se puede entender el sentido del pluralismo democrático como un reconocimiento de derechos. En pocas palabras, la creencia de valor, la tolerancia como reconocimiento de la diferencia y la autonomía de la sociedad respecto a las estructuras del poder (Sartori, 2014, p. 172).

En esta relación que se ha establecido entre Estado y democracia para entender la evolución de los DDHH, es necesario plantear los requisitos para la existencia de la democracia en un Estado y, por tanto, la existencia de la base del respeto a la dignidad humana:

1. El control de las decisiones gubernamentales debe estar constitucionalmente conferido a cargos públicos elegidos. 
2. Los cargos públicos deben elegirse por elecciones frecuentes, ecuánimes, sin uso de la violencia.

3. Derecho al voto para todos los adultos.

4. Derecho a participar en política para todos los adultos.

5. Derecho de expresión de los ciudadanos sin peligro de represalias.

6. Los ciudadanos deben tener acceso a diversas fuentes de información y estas deben existir y estar protegidas.

7. Derecho a formar asociaciones, partidos o grupos de presión independiente.

8. Los cargos públicos elegidos deben ejercer sus poderes de forma independiente y sin interferencia de otros cargos.

9. El gobierno debe autogobernarse con garantía de soberanía, sin constreñimientos impuestos desde el exterior (Del Águila, 1997, p. 156).

Nótese que dichos requisitos son una serie de derechos que tienen sentido político en la medida en que exista el reconocimiento de unos mínimos éticojurídicos en los Estados modernos. Primero, "todos los seres humanos poseen igual dignidad sin ningún tipo de distinción"; segundo, "todos los seres humanos poseen en sentido absoluto la dignidad", es decir, no se puede recusar este principio sin caer en la violación de la dignidad; tercero, la dignidad va unida, en sentido moderno, a la idea de personalidad e identidad personal y cuarto, "la dignidad presupone, para su pleno reconocimiento, un entorno de libertad y justicia social en el que la pluralidad y la diferencia estén salvaguardas" (Suárez, 2004, pp. 239-240).

Lo anterior permite entender que la evolución de los DDHH en los Estados modernos se da desde el reconocimiento de un conjunto de mínimos y de derechos para que en sociedad y dentro de los Estados las personas tengan la garantía de la libertad y de la dignidad humana. Con todo ¿cuál ha sido la manifestación de los DDHH a nivel internacional? Para dar respuesta a esta pregunta, en el siguiente capítulo se abordará la evolución de los DDHH desde algunos hechos históricos asociados a la guerra y que de una u otra forma configuraron el marco normativo internacional de protección de derechos y la humanización de la guerra.

\section{El nivel internacional}

La vigencia internacional contemporánea de los DDHH suele entenderse desde la Declaración de Derechos Humanos de 1948 de la Organización de Naciones 
Unidas (ONU). Esto, porque en Occidente la declaración se convirtió en el sello de derecho internacional para protección de la dignidad humana. No obstante, el objetivo en este aparte es evidenciar algunos hechos que, además de reflejar la evolución de los DDHH, también permiten entender las bases del derecho internacional y, más precisamente, lo que se conoce como la humanización de la guerra.

\section{Las conferencias de la Haya de 1899 y 1907}

En 1815, con el Convenio de Viena, se puso fin a las guerras napoleónicas y se estableció un período de casi cien años de paz en Europa. Este orden internacional del equilibrio de poder fue firmado por las cinco potencias europeas de la época: Gran Bretaña, Austria, Prusia, Rusia y Francia. Estas reconocieron que, para conservar la estabilidad en el continente, era necesario evitar que una sola potencia acumulara todo el poder. No obstante, para 1871 el equilibrio del poder fue puesto a prueba por la misión emprendida por el canciller prusiano Otto Von Bismarck ${ }^{5}$ al lograr la unificación de Alemania.

Cuando llegó al poder el káiser Guillermo, se fracturó la relativa paz en Europa: primero, porque la política exterior se basó en mecanismos hostiles y de competencia y, segundo, porque el nuevo talante alemán creó tensiones con Gran Bretaña, Francia, Rusia e Italia quienes respondieron fortaleciendo sus mecanismos de defensa. A pesar de lo anterior, para 1899 se realizó la Conferencia de Paz de La Haya.

El objetivo de esta conferencia fue establecer mecanismos de solución pacífica de las controversias entre Estados y generar limitaciones al ejercicio de la guerra terrestre. Sin embargo, el escenario europeo estaba caldeado, pues según Kagan (2003) la competencia internacional era permanente (p. 136) y, además, el zar Nicolás II quien había liderado la reunión fue de los primeros promotores de la actualización de equipos militares. Este contexto contradictorio que va desde la unificación alemana hasta el inicio de la Gran Guerra en 1914 se conoce en la historia de las relaciones internacionales como la "paz armada".

La segunda Conferencia de Paz se realizó en 1907, cuando se prohibió el uso de minas antisubmarinos, la utilización de barcos comerciales en la guerra y asuntos atinentes a la guerra naval. Sin embargo, en el período de una conferencia a otra, las potencias no respetaron lo dispuesto. Toda Europa se rearmó debido a que la desconfianza entre los Estados fue creciendo y la Gran Guerra (1914-1919) fue inminente. Lo paradójico fue que en el desarrollo de las

Según Kissinger (2001), Bismarck odiaba el acuerdo de Viena porque ponía a Prusia como el socio menor de Austria en la Confederación Germánica por lo que consideraba que para que surgiera una Prusia grande era necesario destruir el equilibrio. 
hostilidades se utilizaron armas y se implementaron las acciones de guerra que habían sido prohibidas en La Haya y armas que incrementaron el sufrimiento de los soldados. En definitiva, fue el total incumplimiento a los principios de proporcionalidad utilizando todo tipo de armas, gases y el novedoso poder aéreo que solo sería regulados en posteriores acuerdos en 1925 y 1929 (Comité Internacional de la Cruz Roja, 2005, p. 11).

\section{La paz de Versalles y la Sociedad de Naciones}

Cuando terminó la guerra en 1919, más de 20 millones de personas habían muerto, el imperio austrohúngaro desapareció, las coronas rusa, alemana y austriaca cayeron y apareció el interés de establecer un nuevo orden internacional que se cristalizó con la paz de Versalles de 1919 (Kissinger, 2001, p. 213). El presidente de los Estados Unidos, Woodrow Wilson ${ }^{6}$, encabezó esta nueva iniciativa y propuso establecer el orden a partir del concepto de la seguridad colectiva y rechazó el concepto del equilibrio de poder por basarse en la Raison D'etat, es decir, en los intereses nacionales. Esto conllevó a la aparición de la Sociedad de Naciones ${ }^{7}$ que se encargó de establecer y definir los motivos de violación de la estabilidad y la paz internacional.

Este acuerdo internacional permitió una evolución en materia de DDHH, pues la esencia, planteada por Wilson en los catorce, puntos prohibió la esclavitud, se hizo un llamado a acabar con los excesos coloniales y se acordó la autonomía de minorías étnicas y su libre determinación. Aparte de eso, se estableció una corte internacional para juzgar a los criminales de guerra ${ }^{8}$, se estableció la libre navegación de embarcaciones y se inició un proceso para reestablecer las líneas de frontera en Europa (Mejía, 2009, p. 204). De tal forma, la Sociedad de Naciones se concibió "como un grupo de Estados Soberanos que acordaron seguir una serie de prácticas comunes y consultarse por el interés mutuo, especialmente cuando hubiera una amenaza de guerra" (Kagan, 2003, p. 259).

En la actualidad se puede entender la importancia que tuvo las Sociedad de Naciones para el sistema internacional: primero, porque fue un antecedente de principios como la libre determinación de los pueblos y la soberanía, segundo, porque prohibió la guerra como forma de resolver las controversias entre Es-

$6 \quad$ Según Wilson, el orden de Versalles debía estar basado en: un derecho universal y no en el equilibrio; en la integridad nacional y no en la autoafirmación nacional; en la misión especial de los Estados Unidos como faro de la libertad para el resto de la humanidad; en que la política exterior de las democracias es moralmente superior porque el pueblo es, en esencia amante de la paz y por tanto la política exterior debe reflejar las mismas normas morales que la ética personal (Kissinger, 2001, p. 40).

7 Con la Sociedad de Naciones se estableció el orden internacional constitucional o también denominado institucional. En términos formales, este modelo se ha impuesto hasta la actualidad.

$8 \quad$ El káiser Guillermo II fue acusado de incumplir los acuerdos de La Haya de 1889 y 1907. Aunque no fue juzgado formalmente si se creó un precedente para los posteriores juicios de Núremberg (Motta, 2010, p. 10). 
tados, asunto vigente actualmente a través del sistema de la Organización de Naciones Unidas (ONU) con la Resolución 2625; tercero, porque fundó la Corte Permanente de Justicia Internacional la cual entre 1920 y 1940 dirimió cerca de 29 problemas (ONU, s. f., La Corte Permanente..., párr. 5); cuarto, porque en 1919 creó la Organización Internacional del Trabajo (OIT) y en 1924 fueron reconocidos los derechos de los niños; quinto, porque en 1925 se proscribió el uso de gases, armas químicas y biológicas en la guerra (Comité Internacional de la Cruz Roja. CICR, 1925) y, por último, porque para 1926 prohibió la esclavitud (ONU, 1926).

\section{Del pacto Briand-Kellogg a la Conferencia de San Francisco}

El pacto Briand-Kellog ${ }^{9}$ fue firmado por los ministros de relaciones exteriores de Francia -Aristide Briand- y de Estados Unidos -Frank Kellogg- y en él las partes renunciaron al uso de la guerra para resolver sus problemas (Gobbi, s.f., p. 5). Posteriormente otros países miembros de la Sociedad de Naciones se suscribieron $^{10}$ a lo allí pactado excepto Yemen, Arabia Saudita, Brasil, Bolivia y Argentina. Según Ramón (2006) este tratado, en su momento, fue uno de los instrumentos más relevantes en el sistema internacional, pues además de la renuncia a la guerra fue un mecanismo para mantener la paz y solucionó la zona gris dejada por la Sociedad de Naciones que reconocía las guerras y las anexiones de territorio realizadas dentro de los marcos legales (p. 177).

A pesar de los avances, para 1931 inició la antesala de la Segunda Guerra Mundial (1939-1945): Japón invadió la Manchuria en 1931; Adolfo Hitler se proclamó Führer en 1933; la Italia de Mussolini incursionó en el norte de África y Alemania atacó a Polonia en 1939 luego de diferentes anexiones territoriales (Kissinger, 2001; Avilés, 2003, p. 1). En este contexto, los alemanes ya se habían recuperado de las sanciones ${ }^{11}$ impuestas en Versalles gracias a la política de la Realización liderada por el canciller Gustav Streseman y posteriormente por los planes expansionistas y cálculos geopolíticos de Adolfo Hitler. Algunos cálculos señalan que el enfrentamiento de más de setenta países dejó un saldo de más de sesenta millones de muertos.

El fin de la guerra inició en 1944 con la reunión de Dumbarton Oaks en Estados Unidos, donde miembros de este país, la Unión Soviética, Inglaterra, y China, establecieron los objetivos, mecanismos y plan de trabajo de una nueva institución que se encargaría de mantener la paz mundial. Para dar cumplimiento a lo acordado en esta primera reunión, el 25 de abril de 1945 se llevó a cabo la

\footnotetext{
En la actualidad la esencia del tratado está recogida en el capítulo VII de la ONU.

Colombia se adhirió al pacto a través de la Ley 29 de 1930.

11 Según Kissinger (2001) las principales sanciones a Alemania fueron: perder todas sus colonias, reducir su ejército a cien mil voluntarios y la prohibición de tener armas estratégicas (pp. 235-236).
} 
Conferencia de San Francisco, donde participaron los 50 Estados que habían declarado la guerra a Alemania (ONU, s. f., 1945: La conferencia..., párr. 1). Al cierre de la conferencia se dio a conocer la estructura y carta de la ONU que de acuerdo con Kagan (2003) seguían la misma línea de objetivos de la Sociedad de Naciones ${ }^{12}$ : la libre autodeterminación y autonomía, la democracia, el libre comercio y navegación y la expansión de la economía (p. 387). La carta fue aprobada por todos los estados y dejó expresamente señalada la necesidad de mantener la paz, mantener la seguridad mundial, utilizar la guerra en casos específicos de interés colectivo y buscar el desarrollo económico y humano en todo el mundo.

\section{La Declaración Universal y el marco posterior de derechos}

El cénit internacional de los DDHH se alcanzó luego de la II Guerra Mundial, dado que "los líderes del mundo decidieron complementar la Carta de las Naciones Unidas con una hoja de ruta para garantizar los derechos de todas las personas en cualquier lugar y en todo momento" (ONU, s. f., Historia de la redacción..., párr. 2). El resultado fue la Declaración Universal de los Derechos Humanos (DUDH) de 1948. El texto es considerado "la primera declaración mundial sobre la dignidad y la igualdad inherentes a todos los seres humanos" (ONU, s. f., Historia de la redacción..., párr. 1) y contiene derechos como: libertad, vida, igualdad, protección, debido proceso, propiedad, religión, pensamiento, trabajo, educación, etc.

La declaración marcó un nuevo modelo para las relaciones internacionales, basadas en el ser humano y sus derechos y no en los intereses egoístas que llevan a la guerra (Cifuentes, 2008). Con los años ha adquirido relevancia considerable a nivel mundial a partir de nuevos tratados de protección de los DDHH; de la conformación de organismos internacionales, como también de organizaciones no gubernamentales (ONG) defensoras y garantes de derechos en zonas de conflicto, y el desarrollo de doctrinas jurídicas en el derecho internacional.

Para el año de 1949, dadas las atrocidades de los enfrentamientos mundiales, los estados convinieron los cuatro acuerdos de Ginebra (Rey-Schyrr, 1999): el primero abordó el tratamiento de heridos y enfermos en la guerra; el segundo, añadió el tema de los náufragos; el tercero, los prisioneros producto de la confrontación y el cuarto planteó la protección de civiles y no combatientes (CICR, 2012). Más aún, los convenios incluyeron la distinción entre civiles y combatientes, entre personal médico y religioso y las transgresiones y sanciones de los Estados (CICR, 2012).

\footnotetext{
12 No obstante, a diferencia de la Sociedad de Naciones, la ONU tuvo mecanismos adicionales de poder como el Consejo de Seguridad y los cascos. La carta fue aprobada por unanimidad por los miembros y entró a regir a partir de octubre de 1945.
} 
Para 1966 se consolidó la relevancia internacional de la declaración al adoptar el Pacto de Derechos Civiles y Políticos ${ }^{13}$ (PIDCP) y el Pacto de Derechos Sociales y Económicos ${ }^{14}$ (Pidesc). En conjunto, los tres textos son la base de protección de los derechos humanos y conforman La Carta de Derechos Humanos de la ONU (Humanium, s. f., Pactos Internacionales...). Ambos parten de la equidad como principio fundamental de los derechos y de su indivisibilidad, esto es, que son de y para todos los hombres y mujeres, y además cuentan con protocolos facultativos para la garantía de su cumplimiento.

Antes de terminar es necesario señalar que la evolución de los DDHH ha estado cargada de contradicciones pues,

[...] con sus organismos internacionales, sus tribunales internacionales y sus convenciones internacionales, podría resultar exasperante, dada la lentitud con que responde o la repetida incapacidad de alcanzar sus objetivos últimos; sin embargo, no disponemos de ninguna estructura mejor para afrontar estos asuntos. Los tribunales y las organizaciones gubernamentales, por muy internacional que sea su ámbito, siempre se verán obstaculizados por consideraciones geopolíticas. La historia de los derechos humanos demuestra que al final la mejor defensa de los derechos son los sentimientos, las convicciones y las acciones de multitudes de individuos que exigen respuestas acordes con su sentido interno de la indignación (Hunt, 2007, pp. 219-220).

De esta forma Hunt (2007) reconoce que a pesar de la existencia de una serie de mecanismos político-jurídicos de carácter internacional para la protección de derechos, en últimas su garantía real vuelve al nivel individual, es decir, al sentido que, a partir de la observación de la vida común, las personas puedan dar a la situación de los otros desde la empatía.

\section{Conclusiones}

Los DDHH son el principal instrumento de la legitimación política de Occidente. Esta idea está basada en el marco de las relaciones internacionales en la medida en que la cultura Occidental ha impuesto a través del Estado moderno el modelo económico y el modelo internacional, una forma particular de entender las dinámicas de la política internacional. Con todo, en este artículo se pudo evidenciar la evolución política de los DDHH desde la conexión de tres niveles: individual, estatal e internacional, para comprender su relevancia en las relaciones internacionales.

En el primer nivel de análisis se pudo establecer que los DDHH, más allá de su dimensión jurídica y filosófica, tienen sentido porque fueron mecanismos de

\footnotetext{
13 Los principales derechos son: la vida, la libertad, prohibición de la tortura, prohibición de la esclavitud, prohibición de detención arbitraria, el debido proceso y elegir y ser elegido

14 Los principales derechos son: el trabajo, educación, adecuado nivel de vida adecuado y derechos culturales
} 
transformación de la concepción de los individuos y su relación con los demás. Todo esto implicó dos cosas: cambios en la mentalidad y la modificación de las relaciones sociales. Por eso, el origen en el siglo XVIII de los DDHH se debe concebir no como una característica de las personas sino como la posibilidad de ejercerlos, hacerlos valer frente a los otros y convertirlos en una actividad diaria que ha ido adquiriendo un sentido político posteriormente en los Estados modernos.

En el segundo nivel, se evidenció que los DDHH se entienden en el marco de los Estados democráticos liberales. En otras palabras, aquellas estructuras institucionales que buscan limitar los excesos en contra de los individuos, al permitir establecer mecanismos de control y límites al ejercicio del poder político. El reconocimiento de los DDHH dentro de los Estados significó, en últimas, dar un sentido político a las transformaciones humanas del siglo XVIII a partir del reconocimiento de la libertad individual o la dignidad humana, la cual hace parte de los ordenamientos jurídicos nacionales e internacionales.

En el tercer nivel se abordó la vigencia internacional contemporánea de los DDHH al reflexionar más allá de la tradicional concepción de la Declaración de 1948. Se evidenciaron otros hechos históricos de relevancia internacional que, al seguir la misma línea de la dignidad humana, configuraron un marco normativo internacional de protección de derechos que ha tenido el efecto de humanizar la guerra.

No obstante, en este punto existen contradicciones que llevan a pensar los DD. HH. en el nivel individual. Lo relevante de este planteamiento es que existe un reconocimiento de la importancia de los derechos y de sus mecanismos de garantía política-jurídica. Sin embargo, también es evidente que los derechos quedan relegados a un segundo plano en las cuestiones geopolíticas como sucedió en los siglos XIX y XX.

En la actualidad, cuando se dan interacciones entre Estados por la competencia del poder internacional se pueden presentar dos escenarios: uno, donde se invocan los DDHH y se generan violaciones a estos; dos, cuando son utilizados como un mecanismo de sometimiento y poder internacional a otros Estados. Por lo que Hunt (2007) considera que la mejor manera de defender los DDHH es desde la individualidad de cada ser humano en sociedad.

\section{Agradecimientos}

Artículo de reflexión que presenta los resultados de investigación del ejercicio académico del autor en los cursos de pregrado y posgrado de Relaciones Internacionales e Historia y Teoría de la Guerra, los cuales están asociados a la línea 
de investigación Relaciones internacionales, conflictos actuales y cooperación internacional del grupo de investigación en Conflicto y Paz de la Universidad de Medellín.

\section{Referencias}

Avilés, J. (2003). La paz mundial y las lecciones de la historia. Madrid: Real Instituto Elcano.

Beccaria, C (2011). De los delitos y de las penas. México: Fondo de Cultura Económica.

Chevallier, J. (2014). El Estado posmoderno. Bogotá: Universidad Externado.

Cifuentes, E. (2008). Significado e importancia de la declaración universal de derechos humanos en el nuevo siglo. Recuperado de http://www.razonpublica.com

Comité Internacional de la Cruz Roja. CICR. (1925). Protocolo sobre la prohibición del uso en la guerra, de gases asfixiantes, tóxicos o similares y de medios bacteriológicos (GBC). Recuperado de http:// www.icrc.org/spa/resources/documents/misc/treaty-1925-gases-and-bacteriologicalprotocol-5tdm2p.htm

Comité Internacional de la Cruz Roja. CICR. (2005). Derecho Internacional Humanitario. Ginebra, Suiza: Centro de apoyo en comunicación para América Latina.

Comité Internacional de la Cruz Roja. CICR. (2012). Convenios de Ginebra del 12 de agosto de 1949. Recuperado de http://www.icrc.org/spa/assets/files/publications/convenios-gva-esp-2012.pdf

Corte Internacional de Justicia. (1995). Documentación de las Naciones Unidas: guía de investigación. Recuperado de https://www.un.org/depts/dhl/spanish/resguids/specilsp.htm

Del Águila, R. (1997). La democracia. En R. del Águila. (Ed.), Manual de Ciencia Política (pp. 139-157). Madrid: Trotta.

Frankopan, P. (2016). El corazón del mundo: una nueva historia universal. Bogotá: Planeta.

Gobbi, J. (s.f.). El Concepto de conflicto y los medios de Solución de Controversias en el Derecho Internacional. Working Paper Centro Argentino de Estudios Internacionales (58), 1-14

Gray, J. (2004). Al Qaeda y lo que significa ser moderno. Barcelona: Paidós.

Humanium. (s.f.). Pactos Internacionales de 1966. Recuperado de http://www.humanium.org/es/ pacto-1966/

Hunt, L. (2007). La invención de los derechos humanos. Barcelona: Tusquets.

Kagan, D. (2003). Sobre las causas de la guerra y la preservación de la paz. Madrid: Turner.

Kissinger, H. (2001). La diplomacia. Ciudad de México: Fondo de Cultura Económica.

Mejía, J. C. (2009). Un acercamiento al establecimiento de los tribunales internacionales modernos. Prolegómenos, 12(23), 201-219.

Motta, D. (2010). Tránsito del derecho penal internacional desde el Tratado de Versalles y de Núremberg hasta Roma. Meritum, 5(2), 161-186.

Oficina del Alto Comisionado para los Derechos Humanos. OHCHR. (s.f.). Comité de Derechos Humanos. Vigilancia del ejercicio de los derechos civiles y políticos. Recuperado de http://www2.ohchr. org/spanish/bodies/hrc/ 
ONU. (s.f.). Historia de la redacción de la Declaración Universal de Derechos Humanos. Recuperado de http://www.un.org/es/documents/udhr/history.shtml

ONU. (1926). Convención sobre la esclavitud. Recuperado de https://www.ohchr.org/SP/ProfessionalInterest/Pages/SlaveryConvention.aspx

ONU. (1945). Carta de las Naciones Unidas. Recuperado de https://www.acnur.org/fileadmin/ Documentos/BDL/2001/0002.pdf

ONU. (s.f.). Conferencia de Dumbarton Oaks y Yalta. Recuperado de https://www.un.org/es/sections/history-united-nations-charter/1944-1945-dumbarton-oaks-and-yalta/index.html

ONU. (s.f.). Conferencia de San Francisco. Recuperado de https://www.un.org/es/sections/historyunited-nations-charter/1945-san-francisco-conference/index.html

ONU. (s.f.). La Corte Permanente de Justicia Internacional. Recuperado de http://www.un.org/es/ icj/permanent.shtml

Patiño, C. (2005). El origen del poder en Occidente. Bogotá: Siglo del Hombre.

Ramón, C. (2006). Uso de la fuerza y protección de los derechos humanos en un nuevo orden internacional. Valencia: Tirant lo blanch.

Renaut, A. (1993). La era del individuo. Madrid: Destino.

Rey-Schyrr, C. (1999). Los Convenios de Ginebra de 1949: un progreso decisivo (primera parte). Revista Internacional de la Cruz Roja. Recuperado de http://www.icrc.org/spa/resources/documents/ misc/5tdnkz.htm

Sartori, G. (2014) ¿Qué es la democracia? Barcelona: Taurus.

Suárez, J. (2004). Syllabus sobre filosofía política. Medellín: Universidad Pontificia Bolivariana.

Taylor, C. (1996). Las fuentes del yo. Barcelona: Paidós.

Waltz, K. (1959). El hombre, el Estado y la guerra. Buenos Aires: Nova.

Weber, M. (2010). El político y el científico. Ciudad de México: Coyoacán. 